\title{
SISTEM INFORMASI PARIWISATA OBJEK WISATA TUKAD CAMPUHAN TAMPAKSIRING BERBASIS WEB
}

\author{
Rizky Sanjaya, Yoga Adiputra, Ramadika Sudewa Putra dan Krisna Hermawan
}

ITB STIKOM BALI

\begin{abstract}
This study aims to develop a Web-based Tourism Information System for Tukad Campuhan Tampaksiring Tourism Object as a natural tourism object in the Tampaksiring Tourism Village. The tourism information system aims to make it easier for tourists to get information about Tukad Campuhan Tampaksiring Tourism Object. This research is a type of development research with reference to a place / tourism object that still needs to be developed or a tourist object that is still new. The trial subjects in this study were expert subjects, namely the managers of the Tukad Campuhan tourism object, as well as the tourists as potential users of the information system (users). The results of our research directly to the field show that, in the Tukad Campuhan Tourism Object, development is still very necessary, especially in the Information System. Therefore we have the idea to develop a Web-based Information System, in order to make it easier for tourists to get information about this Tukad mixed tourism object.
\end{abstract}

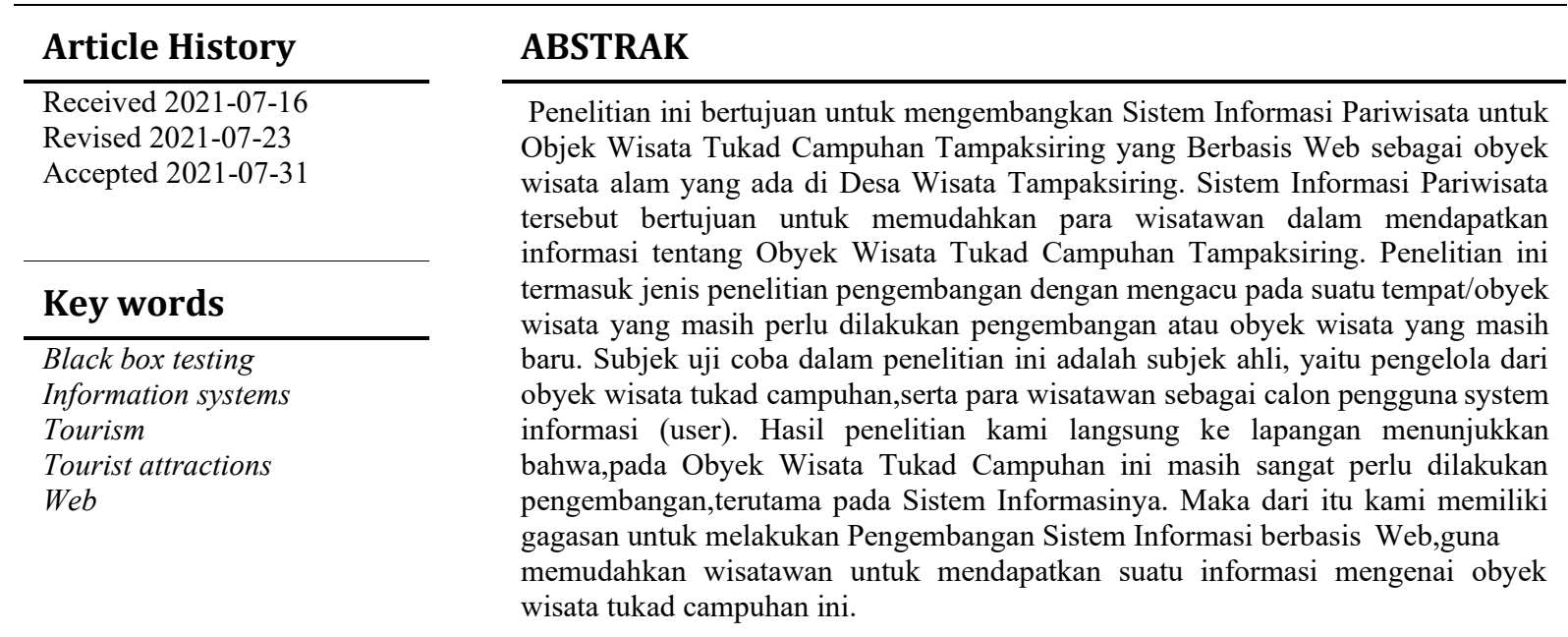

\section{PENDAHULUAN}

Pariwisata merupakan kata yang berasal dari Bahasa sansekerta, kata pariwisata terdiri dari 2 kata yaitu pari dan wisata. Pari yang artinya banyak, berkali-kali, berputar- putar dan wisata yang artinya perjalanan atau berpergian [1]. Oleh karena itu pariwisata dapat diartikan sebagai perjalanan atau kepergian yang kita lakukan secara berulangkali dari satu tempat ke tempat lainnya. Pariwisata juga berarti kegiatan rekreasi yang dilakukan untuk menenangkan pikiran atau diri dari pekerjaan dan juga mencari suasana baru. Salah satu pilihan untuk melakukan kegiatan untuk rekreasi adalah berpergian ke pulau dewata bali.

Sangat banyak ada tempat wisata di Bali, tetapi tidak semua tempat wisata tersebut diketahui atau tidak semua orang dapat dengan mudah mendapatkan informasi mengenai seluruh tempat wisata di bali. Sebagai contoh adalah tempat wisata Tukad Campuhan Tampaksiring.

Objek wisata Tukad Campuhan Tampaksiring merupakan salah satu objek wisata alam yang terletak di Kabupaten Gianyar. Objek wisata Tukad Campuhan Tampaksiring ini dapat dikatakan sebagai objek wisata alam yang baru dikembangkan oleh masyarakat sekitar. Tukad Campuhan Tampaksiring ini adalah sungai yang berada di Tampaksiring yang sekarang dikhususkan untuk orang-orang yang ingin mandi dan bisa juga dijadikan sebagai tempat untuk meditasi. Aliran sungai Tukad Campuhan ini terdiri dari 2 sumber mata air yaitu Mata Air dari Tirta Empul dan Sumber 
Mata Air dari Gunung Kawi,maka dari itulah Tukad Campuhan Tampaksiring sering digunakan untuk mandi atau jika di Bbali disebut dengan melukat oleh para pengunjung.

Selain karena suasana alamnya yang masih asri, akses menuju Tukad Campuhan ini sangatlah baik dan nyaman untuk dilewati. Sekarang Tukad Campuhan sudah dilengkapi dengan Tempat makan, dengan nuansa alam yang masih asri membuat Tukad Campuhan sangat cocok dijadikan tempat untuk berlibur Bersama keluarga dan 2 kerabat. Antusias masyarakat Tampaksiring dalam mengembangkan Tukad Campuhan Sebagai obyek wisata sangat tinggi, terbukti dari dilakukannya pembenahan atau perbaikan Tukad Campuhan serta ditambahkannya lahan parkir bagi para pengunjung. Tetapi objek wisata Tukad Campuhan Tampaksiring ini masih belum diketahui oleh banyak orang, oleh karena itu sangat cocok jika dibuatkan Sistem Informasi Pariwisata yang berbasis web untuk objek wisata Tukad Campuhan Tampaksiring ini.

Sistem Informasi Pariwisata Berbasis Web merupakan pilihan yang sangat tepat untuk dapat membantu objek wisata agar dapat dipromosikan lebih luas serta memudahkan wisatawan untuk mengetahui bagaimana objek wisata yang akan didatanginya dan juga apa saja yang terdapat di objek wisata tersebut. Jika objek wisata Tukad Campuhan Tampaksiring ini memiliki sistem informasi pariwisata berbasis web yang baik, maka kemungkinan besar objek wisata Tukad Campuhan Tampaksiring ini mengalami peningkatan jumlah kunjungan wisatawan.

\section{TINJAUAN PUSTAKA}

\section{Sistem Infromasi}

Sistem informasi merupakan suatu sistem dalam sebuah organisasi yang mempertemukan kebutuhan pengelolaan transaksi harian yang mampu mendukung suatu fungsi operasi organisasi yang bersifat manajerial dengan kegiatan strategi dari suatu organisasi untuk dapat bisa menyediakan kepada pihak luar dengan informasi yang diperlukan untuk pengambilan suatu keputusan. Sistem informasi yang ada dalam sebuah organisasi bisa dikatakan sebagai sebuah sistem yang menyediakan informasi bagi semua tingkatan yang ada dalam organisasi tersebut kapan saja sebuah informasi diperlukan. Sistem informasi harus dikemmbangkan dengan alasan adanya permasalahan berupa adanya ketidak beresan dan pertumbuhan suatu organisasi, untuk meraih kesempatan-kesempatan, dan adanya instruksi.

\section{Pariwisata}

Wardiyanto (2011:3), mengemukakan bahwa secara etimologis kata "pariwisata" diidentikan dengan kata travel dalam bahasa inggris yang diartikan sebagai perjalanan yang dilakukan berkali-kali dari suatu tempat ke tempat lain. Atas dasar itu pula dengan melihat situasi dan kondisi saat ini pariwisata dapat diartikan sebagai suatu perjalanan terencana yang dilakukan secara individu atau kelompok dari suatu tempat ke tempat lain dengan tujuan untuk mendapatkan kepuasan dan kesenangan.

Pariwisata adalah suatu perjalanan yang dilakukan untuk sementara waktu yang diselenggarakan dari suatu tempat ke tempat lain dengan maksud bukan untuk berbisnis ataupun melakukan pekerjaan dan mencari nafkah di tempat yang dikunjungi, tetapi semata-mata untuk memenuhi keinginan yang beraneka ragam.

\section{UML}

Menurut Windu Gata, Grace Unified Modeling Language (UML) adalah bahasa spesifikasi standar yang dipergunakan untuk mendokumentasikan, menspesifikasikan dan membangun perangkat lunak. UML merupakan metodologi dalam mengembangkan sistem berorientasi objek dan juga merupakan alat untuk mendukung pengembangan sistem. Alat bantu yang digunakan dalam perancangan berorientasi objek berbasiskan UML adalah sebagai berikut:

- Use case diagram

Use case diagram merupakan pemodelan untuk perlakuan (behavior) sistem informasi yang akan dibuat. Use case digunakan untuk mengetahui fungsi apa saja yang ada di dalam sistem informasi dan siapa saja yang berhak menggunakan fungsi-fungsi tersebut 
- Diagram Aktivitas (Activity Diagram)

Activity Diagram menggambarkan workflow (aliran kerja) atau aktivitas dari sebuah sistem atau proses bisnis. Simbol-simbol yang digunakan dalam activity diagram yaitu:

Tabel 2.3 simbol diagram aktivitas

\section{Database}

Basis data atau disebut juga sebagai database dalam bahasa inggris adalah kumpulan informasi yang disimpan dalam media elektronik atau komputer secara sistematik. Data tersebut juga diolah sedemikian rupa supaya bisa digunakan dengan mudah. Biasanya, istilah basis data atau database dipelajari dalam ilmu informasi. Pada awalnya, database ada dalam ilmu komputer selanjutnya meluas ke bidang elektronika. Selain itu, pengertian basis data secara sederhana juga bisa diartikan sebagai kumpulan data yang saling berhubungan satu sama lain dan mempunyai penggunaan yang beragam.

\section{Black Box Testing}

Berfokus pada apakah unit program memenuhi kebutuhan (requirement) yang disebutkan dalam spesifikasi. Pada Black Box Testing cara pengujian hanya dilakukan dengan menjalankan atau mengeksekusi unit ataupun modul yang kemudian diamati apakah hasil dari unit itu sesuai dengan proses bisnis yang diinginkan. Jika ada unit yang tidak sesuai outputnya maka untuk menyelesaikannya, diteruskan pada pengujian White Box Testing.

Pengujian Black Box berusaha menemukan kesalahan dalam kategori :

- Fungsi-fungsi yang tidak benar atau hilang

- Kesalahan interface

- Kesalahan dalam struktur data atau akses database eksternal

- Kesalahan kinerja

- Inisialisasi dan kesalahan terminasi

\section{METODE}

\section{Pengumpulan Data}

Pengumpulan data adalah tahapan dimana akan terkumpulnya data yang nantinya dapat digunakan dalam merancang sistem informasi, untuk datanya dapat diperolah melalui beberapa cara yaitu seperti survei dengan narasumber terkait secara langsung atau kita dapat memperoleh data data yang akan dipakai melalui jurnal, buku dan lain-lain. Pengumpulan data ini sangat berguna untuk menambah wawasan dan mengetahui bagaimana cara membuat sistem informasi. Di tahap pengumpulan data ini terdapat teknik yaitu :

- Observasi

Pada tahap observasi dilakukan pengamatan secara langsung dengan berkunjung ke Tukad Campuhan Tampaksiring, disana kami mengamati apasaja yang ada di tempat wisata tersebut serta mencari informasi tetang bagaimana cara pengelola mempromosikan objek wisata ini

- Wawancara

Pada tahap wawancara dilakukan sesi tanya jawab dengan narasumber dengan tujuan agar mendapatkan informasi dan data yang akurat serta agar nantinya dapat mengetahui sistem seperti apa yang harus dibuat.

\section{Analisis Kebutuhan Sistem}

Analisis kebutuhan sistem adalah kegiatan dimana diharuskan untuk mengetahui kendala apa saja yang akan terjadi pada saat pembuatan sistem. Oleh karena itu kita harus menganalisisnya terlebih dahulu agar nantinya sistem yang dibangun merupakan sistem yang baik dan efisien. Sistem ini di buat untuk para pengelola objek wisata dapat menyimpan dan mengolah data dengan baik, dan juga dapat membantu dalam mempromosikan objek wisata tukad campuhan tampaksiring ini. Selanjutnya untuk Analisis dan kebutuhan sistem dapat dibagi menjadi 2 yaitu analisis sistem fungsional dan non fungsional.

1. Analisis Kebutuhan Fungsional 
Analisis kebutuhan fungsional adalah analisi kebutuhan pada sebuah software yang akan di bangun. Adapun beberapa kebutuhannya yaitu :

- Sistem yang nantinya dibuat agar dapat mudah di pahami pengunjung dan pengelola

- Didalam sistem nantinya harus ada halaman login untuk pengelola

- Login menggunakan username dan password

- Sistem dapat menampilkan foto atau video yang berkaitan dengan objek wisata Tukad Campuhan Tampaksiring

- Sistem dapat menjelaskan tentang apa yang ada dan sejarah dari Tukad Campuhan Tampaksiring

- Sistem dapat menampilkan informasi mengenai lokasi objek wisata serta akun media sosial objek wisata

2. Analisis Kebutuhan Non Fungsional

Analisis kebutuhan non fungsional adalah analisis kebutuhan pada alat-alat serta fitur yang digunakan nantinya pada suatu sistem. Adapun beberapa kebutuhannya yaitu :

- Perangkat keras dengan spesifikasi minimal processor intel dual core, RAM 514 MB, Harddisk $1 \mathrm{~GB}$, dan juga jaringan internet yang lancar.

- Perangkat lunak atau sistem operasi minimal windows 7 dan juga di lengkapi dengan Web Browser (Google Chrome, Mozilla Firefox, dan lainnya)

\section{Perancangan Desain Sistem}

Perancangan desain sistem ini dilakukan menggunkan beberapa metode desain contohnya use case diagram, activity diagram, serta desain interface.

\section{Implementasi Sistem}

Implementasi sistem adalah tahapan yang dilakukan sesudah analisis kebutuhan sistem dan perancangan desain sistem. Di implementasi sistem ini akan dikembangkan atau di implementasikan ke dalam sebuah sistem agar nantinya dapat digunakan oleh pengelola dan para calon pengunjung objek wisata tukad campuhan.

\section{Pengujian Sistem}

Pengujian sistem pada sistem ini menggunakan metode Black Box Testing, Black Box Testing ini digunakan untuk menguji input dan output dari sistem dan juga digunakan untuk mengetahui apakah ada kesalahan pada sistem.

\section{Penulisan Laporan}

Di tahapan penulisan laporan merupakan tahapan dimana penggabungan atau ramkuman dokumen dari analisis kebutuhan sistem, perancangan desain sistem, implementasi pembuatan sistem dan pengujian sistem.

\section{HASIL DAN PEMBAHASAN}

\section{Hasil Analisis Kebutuhan Sistem}

Pada tahapan ini dilakukan analisis yang bertujuan untuk mengetahui siapa user atau pengguna dari sistem yang dibuat, data apa saja yang bisa di akses, dan apa saja yang bisa dilakukan oleh user atau pengguna pada sistem ini (bagaimana bisa terjadinya hal tersebut). Tahapan ini dapat dibagi menjadi 3 yaitu :

1. Analisis Pengguna

Pada tahapan ini akan ada analisis terhadap pengguna yang ada yaitu admin, dan juga pengunjung selanjutnya akan disajikan pada tabel Analisis Pengguna.

Tabel 1. Analisis Pengguna

\begin{tabular}{|l|l|l|}
\hline No & Pengguna & Keterangan \\
\hline 1 & Admin & $\begin{array}{l}\text { Admin ini adalah orang pilihan yang bertugas untuk } \\
\text { mengatur penyimpanan data pengunjung, dan lainnya. }\end{array}$ \\
\hline
\end{tabular}




\begin{tabular}{|l|l|l|}
\hline 2 & Pengunjung & $\begin{array}{l}\text { Pelanggan adalah orang yang mengunjungi web melalui } \\
\text { sebuah sistem serta menginputkan tentang informasi } \\
\text { username dan password untuk login }\end{array}$ \\
\hline
\end{tabular}

\section{Analisis Data}

Pada tahapan ini semua pengguna (admin dan pengunjung) memiliki akses data-data yang ada pada sistem tetapi tidak semua, tergantung dari pengguna yang mengakses. Berikut data yang dapat di akses disajikan dalam bentuk table Analisis Data.

Tabel 2. Analisis Data

\begin{tabular}{|l|l|l|}
\hline No & Data & Keterangan \\
\hline 1 & Laporan & Terdapat data dari pengunjung yang diberikan kepada admin \\
\hline 2 & Pengunjung & $\begin{array}{l}\text { Terdapat data dari pengunjung, contohnya id pengunjung, } \\
\text { nama, alamat, dan juga no telp }\end{array}$ \\
\hline 3 & Foto objek wisata & $\begin{array}{l}\text { Terdapat data apa saja yang ada di objek wisata, ini dapat } \\
\text { dilihat oleh semua orang }\end{array}$ \\
\hline
\end{tabular}

3. Analisis Proses

Ditahapan ini akan dijelaskan apa saja proses yang ada pada admin dan pengunjung, disajikan dalam bentuk tabel Analisis Proses.

Tabel 3. Analisis Proses

\begin{tabular}{|l|l|l|}
\hline No & Proses & Keterangan \\
\hline 1 & Login & $\begin{array}{l}\text { Merupakan proses dimana diharuskan memasukkan } \\
\text { username dan juga password, proses ini dilakukan oleh } \\
\text { admin dan juga pengunjung }\end{array}$ \\
\hline 2 & $\begin{array}{l}\text { Mengambil dan } \\
\text { merubah data objek } \\
\text { wisata }\end{array}$ & $\begin{array}{l}\text { Merupakan proses yang hanya dapat dilakukan oleh owner } \\
\text { untuk mengambil data dari pengeluaran dan juga } \\
\text { pemasukan }\end{array}$ \\
\hline
\end{tabular}

\section{Perancangan Sistem}

Pada tahapan ini dilakukan proses pembuatan use case diagram, dan juga activity diagram.

1. Use Case Diagram

Pada perancangan sistem informasi ini terdapat 2 use case diagram dibuat yaitu use case diagram user dan admin.

2. Activity Diagram

Pada percanganan sistem ini terbagi menjadi dua activity diagram, yaitu activity diagram dari segi admin dan user. Yaitu sebagai berikut:

a. Activity diagram user

\begin{tabular}{|c|c|}
\hline user & web \\
\hline & \\
\hline Halaman utama & \\
\hline & \\
\hline
\end{tabular}


Jurnal Riset Inovasi Bidang Informatika Dan Pendidikan Informatika (KERNEL)

Vol. 2, No. 1, Agustus 2021

ISSN: 2774-4345
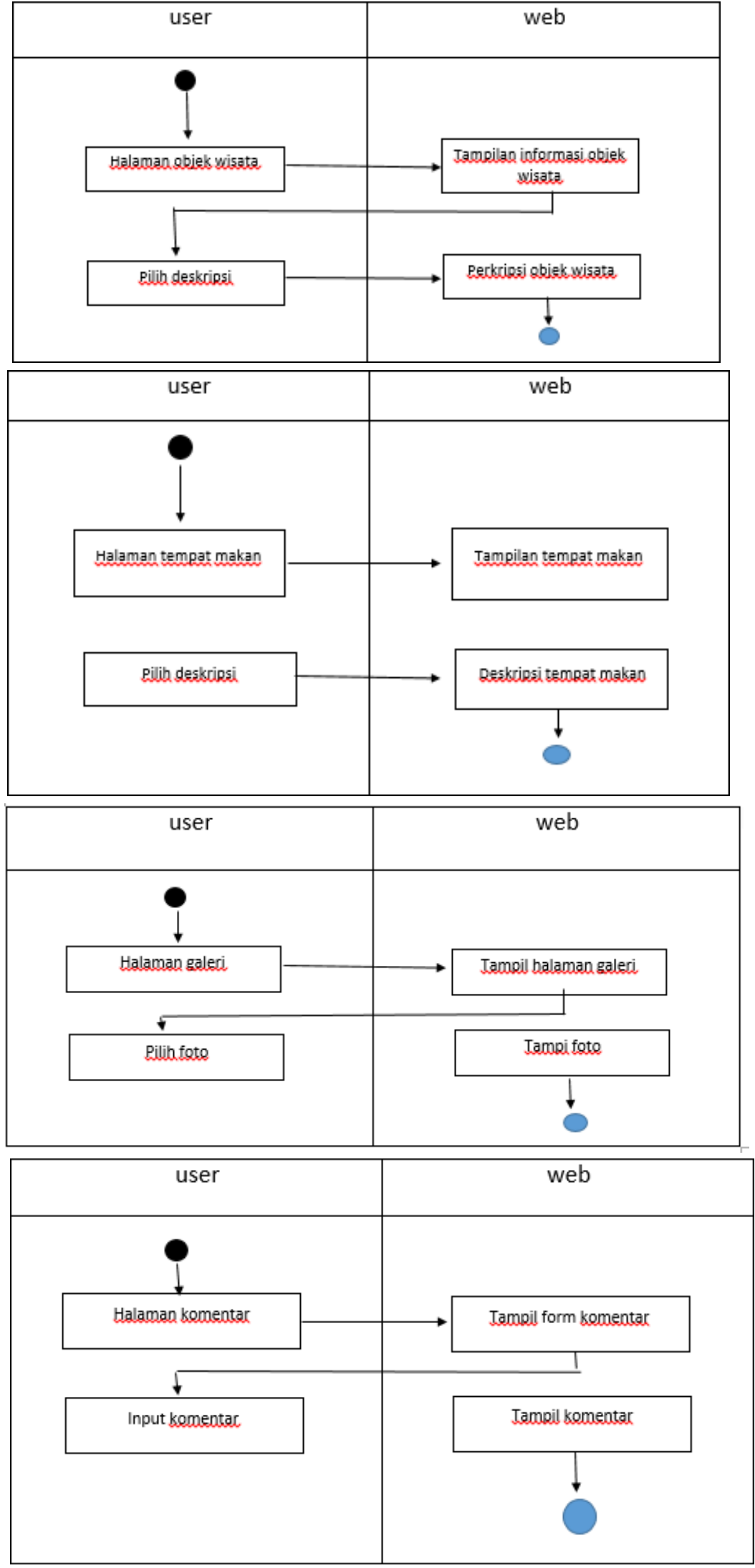

Gambar 1. Activity diagram user 
Jurnal Riset Inovasi Bidang Informatika Dan Pendidikan Informatika (KERNEL)

Vol. 2, No. 1, Agustus 2021

ISSN: $2774-4345$

b. Activity Diagram Admin
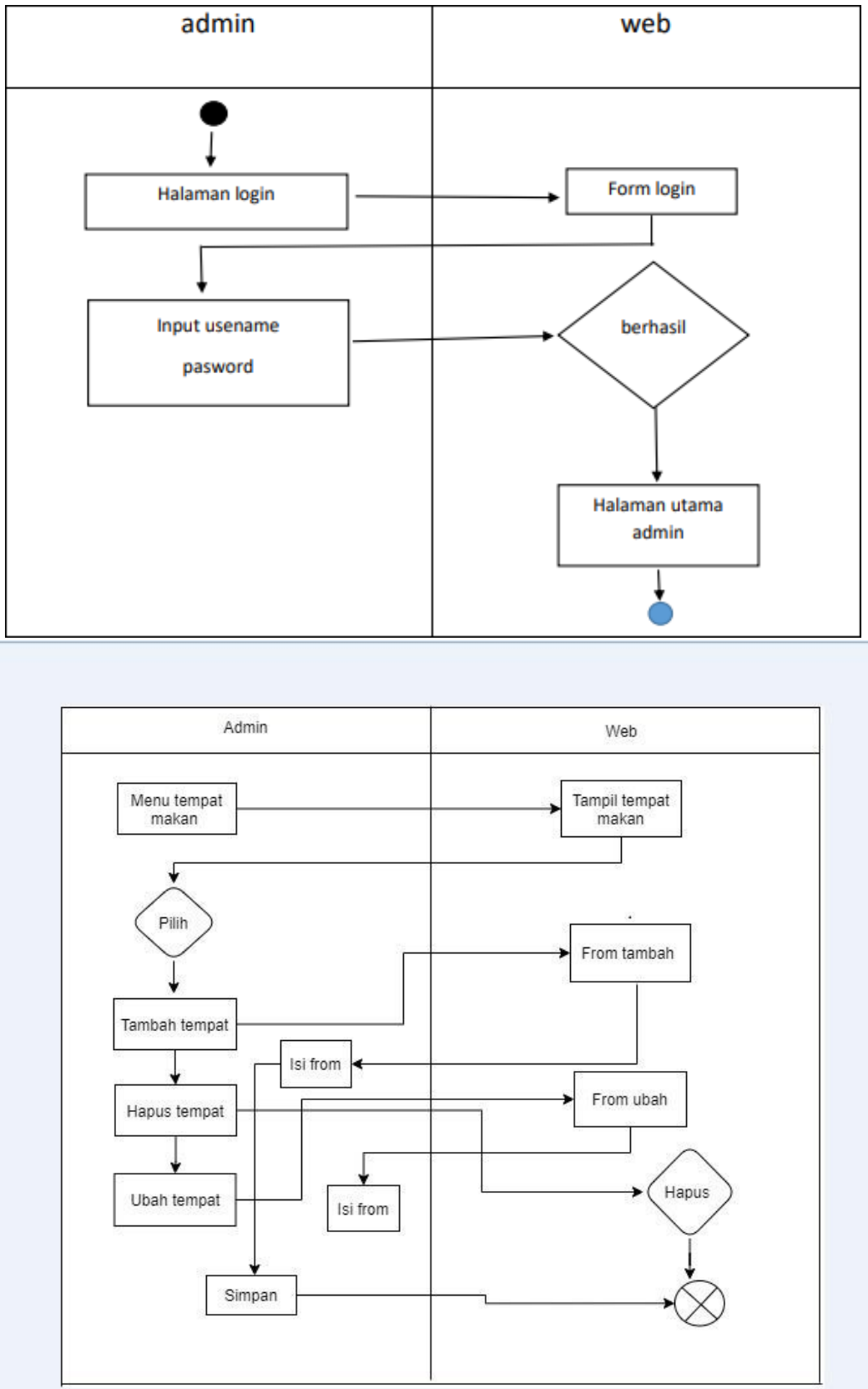


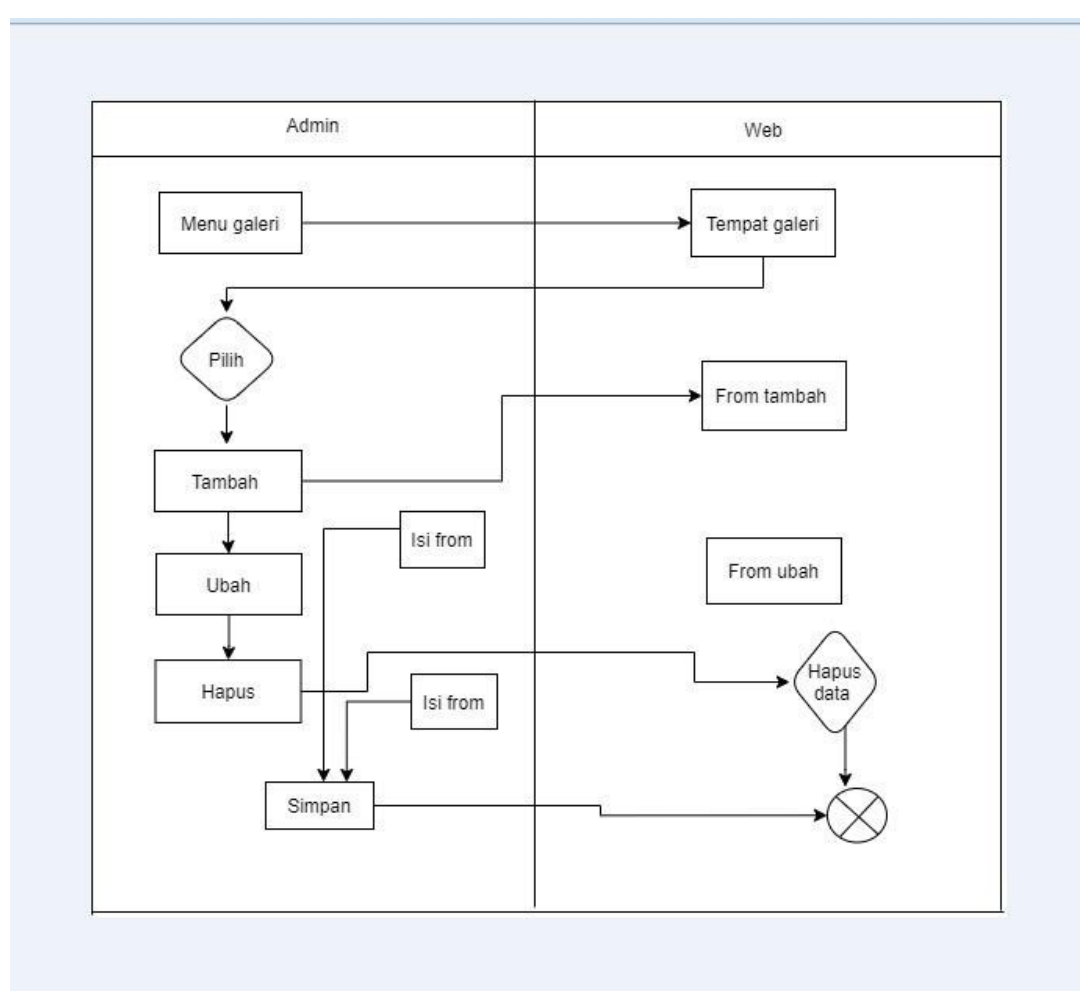

Gambar 2. Activity Diagram Admin

\section{Perancangan Interface}

Pada tahapan perancangan interface ini merupakan tahapan dimana kami akan merancang bagaimana tampilan atau desain yang akan ada pada sistem dan kami akan mengkonfirmasi terlebih dahulu kepada owner atau pengguna untuk perancangannya.

\section{Tampilan Sistem}

Tampilan sistem adalah suatu bentuk hasil dari sistem yang telah selesai dikembangkan yang sesuai dengan tahapan desain sistem. Dalam penelitian ini terdapat dua level pengguna sistem informasi yaitu admin dan user. Dimana admin sebagai pengelola sistem secara khusus, dan user adalah sebagai pengguna secara umum.

\section{Hasil Pengujian}

Untuk ditahapan hasil pengujian ini akan menggunakan metode Black Box Testing dimana metode ini digunakan untuk mengetahuin apakah sistem ini sudah berjalan sebagaimana mestinya atau sistem ini masih ada kekurangannya. Berikut kami tampilkan hasil pengujian pada halaman yang ada di sistem ini.

1. Halaman utama

Tabel 4. Halaman Utama

\begin{tabular}{|l|l|l|l|l|}
\hline No & Kelas Uji & Diharapkan & Hasil & Keterangan \\
\hline 1 & Tampilan & $\begin{array}{l}\text { Dapat } \\
\text { menampilkan } \\
\text { halaman utama }\end{array}$ & $\begin{array}{l}\text { Sistem berhasil } \\
\text { menampilkan } \\
\text { halaman utama }\end{array}$ & Sesuai \\
\hline 2 & $\begin{array}{l}\text { Menampilkan } \\
\text { komentar }\end{array}$ & $\begin{array}{l}\text { Dapat } \\
\text { menampilkan }\end{array}$ & $\begin{array}{l}\text { Sistem berhasil } \\
\text { menampilkan }\end{array}$ & Sesuai \\
\hline
\end{tabular}




\begin{tabular}{|c|c|c|c|c|}
\hline & & $\begin{array}{l}\text { komentar yang } \\
\text { ada }\end{array}$ & $\begin{array}{l}\text { komentar yang } \\
\text { ada }\end{array}$ & \\
\hline 3 & $\begin{array}{l}\text { Menambahkan } \\
\text { komentar }\end{array}$ & $\begin{array}{l}\text { Dapat } \\
\text { menambahkan } \\
\text { komentar }\end{array}$ & $\begin{array}{l}\text { Sistem berhasil } \\
\text { menambahkan } \\
\text { komentar }\end{array}$ & Sesuai \\
\hline 4 & $\begin{array}{l}\text { Klik menu } \\
\text { Tukad } \\
\text { campuhan }\end{array}$ & $\begin{array}{l}\text { Dapat } \\
\text { menampilkan } \\
\text { halaman tukad } \\
\text { campuhan }\end{array}$ & $\begin{array}{l}\text { Sistem berhasil } \\
\text { menampilkan } \\
\text { halaman tukad } \\
\text { campuhan }\end{array}$ & Sesuai \\
\hline 5 & $\begin{array}{l}\text { Klik menu } \\
\text { tempat makan }\end{array}$ & $\begin{array}{l}\text { Dapat } \\
\text { menampilkan } \\
\text { halaman tempat } \\
\text { makan }\end{array}$ & $\begin{array}{l}\text { Sistem berhasil } \\
\text { menampilkan } \\
\text { halaman tempat } \\
\text { makan }\end{array}$ & Sesuai \\
\hline 6 & $\begin{array}{l}\text { Klik menu } \\
\text { tempat galeri }\end{array}$ & $\begin{array}{l}\text { Dapat } \\
\text { menampilkan } \\
\text { halaman galeri }\end{array}$ & $\begin{array}{l}\text { Sistem berhasil } \\
\text { menampilkan } \\
\text { halaman galeri }\end{array}$ & Sesuai \\
\hline 7 & $\begin{array}{l}\text { Klik menu } \\
\text { login }\end{array}$ & $\begin{array}{l}\text { Dapat } \\
\text { menampilkan } \\
\text { halaman login }\end{array}$ & $\begin{array}{l}\text { Sistem berhasil } \\
\text { menampilkan } \\
\text { halaman login }\end{array}$ & Sesuai \\
\hline
\end{tabular}

2. Halaman Login Admin

Tabel 5. Halaman Login Admin

\begin{tabular}{|l|l|l|l|l|}
\hline No & Kelas Uji & Diharapkan & Hasil & Keterangan \\
\hline 1 & Tampilan & $\begin{array}{l}\text { Dapat } \\
\text { menampilkan } \\
\text { halaman login }\end{array}$ & $\begin{array}{l}\text { Sistem berhasil } \\
\text { menampilkan } \\
\text { halaman login }\end{array}$ & Sesuai \\
\hline 2 & $\begin{array}{l}\text { Input } \\
\text { pasername dan } \\
\text { benar }\end{array}$ & $\begin{array}{l}\text { Langsung } \\
\text { membuka } \\
\text { halaman yang } \\
\text { ingin diakses }\end{array}$ & $\begin{array}{l}\text { Sistem berhasil } \\
\text { membuka } \\
\text { halaman yang } \\
\text { ingin diakses }\end{array}$ & Sesuai \\
\hline 3 & $\begin{array}{l}\text { Input } \\
\text { username dan } \\
\text { password yang } \\
\text { salah }\end{array}$ & $\begin{array}{l}\text { Dapat } \\
\text { menampilkan } \\
\text { text dimana } \\
\text { berisi username } \\
\text { dan password } \\
\text { salah }\end{array}$ & $\begin{array}{l}\text { Sistem berhasil } \\
\text { menampilkan text } \\
\text { dimana berisi } \\
\text { username dan } \\
\text { password salah }\end{array}$ & Sesuai \\
\hline
\end{tabular}




\section{KESIMPULAN}

Dari hasil penelitian yang kami lakukan langsung ke lapangan,kami dapat menarik kesimpulan bahwa tujuan dari Pengembangan Obyek Wisata Tukad Campuhan Tampaksiring adalah sebagai berikut :

- Untuk memperkenalkan Obyek Wisata Tukad Campuhan Tampaksiring

- Untuk menginformasikan seluruh layanan dan jasa di Tukad Campuhan Tampaksiring

- Untuk meningkatkan kunjungan wisatawan di Obyek Wisata Tukad Campuhan Tampaksiring

- Layanan yang dikembangkan untuk mengetahui informasi tentang Obyek Wisata Tukad Campuhan bisa melalui situs web yang masih dalam proses pengembangan

- Sasaran dari Sistem Informasi Pariwisata untuk Obyek Wisata Tukad Campuhan Berbasis Web adalah pengguna (User). Pengguna (User) tersebut meliputi : Wisatawan Lokal,Wisatawan Mancanegara dan bahkan Masyarakat umum di daerah Tampaksiring dan sekitarnya. Jadi informasi mengenai Obyek Wisata Tukad Campuhan dapat diakses oleh seluruh wisatwan dan masayarakat.

\section{DAFTAR PUSTAKA}

[1] Drs. Ida Bagus Ketut Astina, M.Si, ”Analisis Pariwisata”. Vol. 13, No. 1, 2013

[2] Yuda Tunggal Wibowo, “Aplikasi Sistem Informasi Tempat Wisata Jawa Tengah Berbasis Web". 2016

[3] Oni Yuliani, Joko Prasojo, "Rancang Bangun Sistem Informasi Obyek Wisata Berbasis Web Menggunakan Metode User Centered Design (Ucd)”. Vol. 7, No. 2, November 2015

[4] Muhammad Haykal, "Perancangan Dan Pembuatan Sistem Informasi Wisata Berbasis Website Di Dinas Pariwisata Dan Kebudayaan Kabupaten Pidie”. 2020

[5] Rintha Prasetyo, "Sisitem Informasi Pariwisata Daerah Kabupaten Wonogiri Berbasis Web". 2011

[6] Ari Nadya Puriwigati, "SISTEM MANAJEMEN BASIS DATA". 2019

[7] Ade Hendini, "Pemodelan Uml Sistem Informasi Monitoring Penjualan Dan Stok Barang (Studi Kasus: Distro Zhezha Pontianak)". Vol. 4, No. 2 Desember 2016 